\title{
Time Scale for Scour Beneath Pipelines Due to Long-Crested and Short-Crested Nonlinear Random Waves Plus Current
}

\author{
Dag Myrhaug ${ }^{1, *}$ and Muk Chen Ong ${ }^{2}$ (D) \\ 1 Department of Marine Technology, Norwegian University of Science and Technology (NTNU), \\ 7491 Trondheim, Norway \\ 2 Department of Mechanical and Structural Engineering and Materials Science, University of Stavanger, \\ 4036 Stavanger, Norway; muk.c.ong@uis.no \\ * Correspondence: dag.myrhaug@ntnu.no; Tel.: +47-73595527
}

Citation: Myrhaug, D.; Ong, M.C. Time Scale for Scour Beneath Pipelines Due to Long-Crested and Short-Crested Nonlinear Random Waves Plus Current. J. Mar. Sci. Eng. 2021, 9, 114. https://doi.org/ $10.3390 /$ jmse 9020114

Academic Editor: Spyros

A. Mavrakos

Received: 3 December 2020

Accepted: 14 January 2021

Published: 22 January 2021

Publisher's Note: MDPI stays neutral with regard to jurisdictional claims in published maps and institutional affiliations.

Copyright: (c) 2021 by the authors. Licensee MDPI, Basel, Switzerland. This article is an open access article distributed under the terms and conditions of the Creative Commons Attribution (CC BY) license (https:// creativecommons.org/licenses/by/ $4.0 /)$.

\begin{abstract}
This article derives the time scale of pipeline scour caused by 2D (long-crested) and 3D (short-crested) nonlinear irregular waves and current for wave-dominant flow. The motivation is to provide a simple engineering tool suitable to use when assessing the time scale of equilibrium pipeline scour for these flow conditions. The method assumes the random wave process to be stationary and narrow banded adopting a distribution of the wave crest height representing 2D and 3D nonlinear irregular waves and a time scale formula for regular waves plus current. The presented results cover a range of random waves plus current flow conditions for which the method is valid. Results for typical field conditions are also presented. A possible application of the outcome of this study is that, e.g., consulting engineers can use it as part of assessing the on-bottom stability of seabed pipelines.
\end{abstract}

Keywords: pipelines; time scale; equilibrium scour depth; nonlinear irregular waves and current; 2D waves; 3D waves; stochastic method

\section{Introduction}

This article addresses the time scale of pipeline scour due to 2D (long-crested) and 3D (short-crested) nonlinear irregular waves and current with the objective of providing a method suitable to use for the practical engineering assessment of pipeline scour. Pipelines originally placed, e.g., on plane beds, will experience the seabed conditions change, i.e., the bed may be flat or with ripples; they may be partly or fully buried or surrounded by scour holes. These changed conditions are due to the complex flow generated by waves plus current and the interaction with the pipeline and the seabed. Real waves are characterized by three-dimensional stochastic features that should be accounted for.

To the best of our knowledge, no study exists in the open literature on the investigation of the time scale for scour beneath pipelines caused by 2D and 3D nonlinear irregular waves plus current. Previously, Myrhaug et al. [1] provided the time scale for the equilibrium scour depth beneath pipelines exposed to 2D and 3D nonlinear irregular waves. Thus, this work is a continuation by extending the method to cover combined waves and current.

The background and details of pipeline scour are provided by, e.g., Whitehouse [2] as well as Sumer and Fredsøe [3], including literature reviews up to that date. Until now, most studies have focused on experimental and numerical work on the equilibrium scour depth beneath pipelines caused by pure current, pure waves and combined waves and current. Exceptions are the recent works of Larsen et al. [4], Zhang et al. [5] and Zang et al. [6] that all three addressed the time scale of equilibrium pipeline scour for waves plus current. Larsen et al. [4] provided an analytical formula for pipeline scour for regular waves plus current based on numerical simulations. Zhang et al. [5] presented a practical time scale formula for regular waves plus current based on small- and large-scale recirculating flume tests. Zang et al. [6] provided results on the time scale of local scour below a partially 
buried pipeline under combined waves and currents with oblique incident angle based on large-scale flume tests.

Furthermore, most of the works on pipeline scour have considered current alone, regular waves alone, and combined regular waves and current, except Sumer and Fredsøe [7], who provided results from an experimental investigation on scour beneath pipelines exposed to random waves plus current. Myrhaug and Ong [8] reviewed the authors' works on 2D irregular wave-induced equilibrium scour around marine structures, also comparing with experimental data for irregular wave-induced scour. Myrhaug and Ong [9] provided an approach for calculating the maximum equilibrium scour depth below pipelines due to 2D and 3D nonlinear irregular waves alone.

The aim here is to present a method for estimating the time scale of pipeline scour beneath pipelines exposed to 2D and 3D nonlinear irregular waves and current that can be used as part of an engineering tool when assessing pipeline scour. Results are obtained adopting the Larsen et al. [4] parameterized time scale formula for pipeline scour valid for regular waves plus current jointly with a stochastic method. The random wave process is assumed to be stationary and narrow banded, and nonlinearity is included using the wave crest height distribution given by Forristall [10] covering 2D and 3D second-order nonlinear irregular waves. The Larsen et al. [4] time scale formula is based on best fit to numerical simulations using a fully coupled hydrodynamic and morphologic numerical model based on incompressible Reynolds-averaged Navier-Stokes equations, including a $k-\omega$ turbulence closure and seabed morphology. The Forristall [10] parametric crest height distribution is based on using second-order theory including both sum-frequency and difference-frequency effects performed for 2D and 3D irregular waves.

The article contains an Introduction, followed by Section 2 giving the background for linear waves plus current. Section 3 presents the results of the time scale for nonlinear random waves plus current by first giving the theoretical background (Section 3.1), and then providing the outline of the stochastic method (Section 3.2). Section 4 gives results and discussion by first providing a parameter study (Section 4.1) and then giving an example of calculation (Section 4.2). The summary and conclusions are given in Section 5.

\section{Background for Linear Waves Plus Current}

From observations, it appears that a certain amount of time is required for an equilibrium scour to develop. This time $T$, referred to as the time scale of the scour process, is defined by (Sumer and Fredsøe [3])

$$
S_{t}=S\left(1-\exp \left(\frac{t}{T}\right)\right)
$$

where $S$ is the equilibrium scour depth corresponding to the equilibrium situation, and $S_{t}$ is the instantaneous scour depth at time $t$.

The dimensionless time scale $T^{*}$ is (Sumer and Fredsøe [3])

$$
T^{*}=\frac{\left(g(\gamma-1) d_{50}^{3}\right)^{1 / 2}}{D^{2}} T
$$

where $g$ is the acceleration due to gravity, $\gamma=r_{s} / r$ is the sediment grain density $\left(r_{s}\right)$ to fluid density $(r)$ ratio, $d_{50}$ is the medium grain size diameter, and $D$ is the pipeline diameter.

The dimensionless time scale for the equilibrium scour depth beneath pipelines in regular waves and current is given by the following formula based on best fit to numerical simulations (Larsen et al. [4]):

$$
\begin{gathered}
T^{*}=F\left(U_{c w}\right) \theta_{w c}^{-\frac{5}{3}} \\
F\left(U_{c w}\right)=\frac{1}{50}+0.015\left[e^{-350\left(U_{c w}-0.5\right)^{2}}+e^{-25\left(U_{c w}-0.53\right)^{2}}\right]
\end{gathered}
$$


Here,

$$
U_{c w}=\frac{U_{c}}{U_{c}+U}
$$

where $U_{c}$ is the current velocity, $U$ is the undisturbed linear orbital velocity amplitude near the seabed, and $F\left(U_{c w}\right)=1 / 50$ for both waves alone $\left(U_{c w}=0\right)$ and current alone $\left(U_{c w}=1\right)$. Equation (3) is valid for live-bed scour for $\theta_{w c}>\theta_{c r}, \theta_{w c}$ is the undisturbed Shields parameter for combined waves plus current flow, and $\theta_{c r}$ is the threshold value of motion at a flat bed, i.e., $\theta_{c r} \approx 0.05$. Larsen et al. [4] calculated $\theta_{w c}$ using an equivalent formula to that given by Soulsby [11] (see Larsen et al. [4] for more details). However, here waves and current for wave-dominant situations will be considered, and thus $\theta_{w c}$ in Equation (3) is replaced with the undisturbed Shields parameter.

$$
\theta=\frac{\tau_{w}}{\rho g(\gamma-1) d_{50}}
$$

Here, $\tau_{w}$ is the maximum bottom shear stress within a wave cycle under waves taken as

$$
\frac{\tau_{w}}{\rho}=\frac{1}{2} f_{w} U^{2}
$$

and $f_{w}$ is the friction factor, which here is adopted from Myrhaug et al. [12] valid for waves and current for wave-dominant situations (see Myrhaug et al. [12]).

$$
\begin{gathered}
f_{w}=c\left(\frac{A}{z_{0}}\right)^{-d} \\
(c, d)=(18,1) \text { for } 20 \lesssim \mathrm{A} / \mathrm{z}_{0} \lesssim 200 \\
(c, d)=(1.39,0.52) \text { for } 200 \lesssim A / z_{0} \lesssim 11,000 \\
(c, d)=(0.112,0.25) \text { for } 11,000 \lesssim A / z_{0}
\end{gathered}
$$

where $A=U / \omega$ is the near-bed orbital displacement amplitude, $\omega=2 \pi / T_{w}$ is the angular wave frequency, $T_{w}$ is the wave period, and $z_{0}=d_{50} / 12$ is the bed roughness. Using this friction factor for rough turbulent flow gives the advantage of deriving the stochastic approach analytically. Furthermore, $A$ is given in terms of the linear wave amplitude $a$ by

$$
A=\frac{a}{\sinh k h}
$$

with $h$ as the water depth, and $k$ as the wave number obtained by the dispersion relationship $\omega^{2}=g k$ tanh $k h$. For colinear waves and current the dispersion relationship is $\omega=k U_{c}+(g k \tanh k h)^{0.5}$ (see, e.g., Soulsby [11]), determining $k$ for known values of $\omega, U_{c}$ and $h$ However, for wave-dominant flow, the effect of $U_{c}$ on $k$ is small, i.e., $k$ is obtained for $U_{c}=0$. Here, wave-dominant flow is considered for $U_{c w} \leq 0.5$. It should be noted that Equation (4) has its maximum for $U_{c w}=0.5$, i.e., $F\left(U_{c w}=0.5\right)=0.05$.

\section{Time Scale for Nonlinear Irregular Waves and Current}

\subsection{Theoretical Background}

The theoretical background is similar to that given in Myrhaug et al. [1] and is summarized here for the sake of completeness.

Nonlinear waves are represented by Stokes second-order waves where the nonlinearity is mainly due to the larger velocity beneath the wave crest (i.e., crest velocity) than beneath the wave trough (i.e., trough velocity). It is likely that the larger crest velocity causes the scour, rather than the average of the crest and trough velocities (i.e., corresponding to the linear wave velocity (Catano-Lopera and Garcia [13])). Consequently, the time scale for single irregular Stokes second-order waves is given by Equations (2)-(5) replacing $U$ with the maximum orbital velocity near the seabed beneath the wave crest, $U_{m}$. 
Consider a fixed location in a sea state containing stationary narrow-band irregular waves in finite water depth $h$ consistent with Stokes second-order regular waves. Then, the dimensionless nonlinear crest height, $w_{c}=\eta_{c} / a_{r m s}$, and the dimensionless nonlinear maximum horizontal particle velocity at the seabed, $\hat{U}_{m}=U_{m} / U_{r m s}$, are (Dean and Dalrymple [14])

$$
\begin{aligned}
w_{c} & =\hat{a}+O\left(k_{p} a_{r m s}\right) \\
\hat{U}_{m} & =\hat{a}+O\left(k_{p} a_{r m s}\right)
\end{aligned}
$$

Here, $\hat{a}=a / a_{r m s}$ is the dimensionless linear wave amplitude, the wave amplitude $\mathrm{a}$ is normalized with the rms (root-mean-square) value $a_{r m s}$, and

$$
U_{r m s}=\frac{\omega_{p} a_{r m s}}{\sinh k_{p} h}
$$

The second-order (nonlinear) terms are represented by $\mathrm{O}\left(k_{p} a_{r m s}\right)$ and proportional to $k_{p} a_{r m s}$, i.e., a characteristic wave steepness of the sea state. Here, $k_{p}$ is the wave number associated with the spectral peak frequency obtained from the dispersion relationship for linear waves (valid for Stokes second-order waves as well)

$$
\omega_{p}^{2}=g k_{p} \tanh k_{p} h
$$

Next, the inversion of Equation (13), i.e., $\hat{a}=w_{c}-\mathrm{O}\left(k_{p} a_{r m s}\right)$ is substituted in Equation (14) giving $\hat{U}_{m}=w_{c}+\mathrm{O}\left(k_{p} a_{r m s}\right)$. Thus, $\hat{a}$ is replaced with $w_{c}$ in the linear term of $U_{m}$ since the error is of second order. By neglecting terms of $\mathrm{O}\left(k_{p} a_{r m s}\right)$, the maximum near-bed orbital velocity beneath the wave crest in dimensional form becomes

$$
U_{m}=\frac{\omega_{p} \eta_{c}}{\sinh k_{p} h}
$$

Furthermore, $A_{m}=U_{m} / \omega_{p}$ is the maximum orbital displacement near the seabed beneath the wave crest, and $\hat{A}_{m}=A_{m} / A_{r m s}$ is the dimensionless maximum orbital displacement near the seabed, where

$$
A_{r m s}=\frac{a_{r m s}}{\sinh k_{p} h}
$$

and

$$
\omega_{p}=\frac{U_{m}}{A_{m}}=\frac{U_{r m s}}{A_{r m s}}
$$

by combining Equations (15) and (17).

\subsection{Outline of the Stochastic Method}

As in Myrhaug et al. [1], it is assumed that the highest waves are responsible for the scour in the stationary narrow-band sea state considered. Moreover, the sea state is assumed to have lasted long enough to develop the equilibrium scour depth. Here, the considered highest waves are those exceeding the probability $1 / n, w_{c 1 / n}$ (i.e., $\left.1-P\left(w_{c 1 / n}\right)=1 / n\right)$, where $P\left(w_{c}\right)$ is the cumulative distribution function (cdf) of the dimensionless crest height $w_{c}$ adopted from Forristall [10] (see Equation (A1) in Appendix A).

The statistical characteristic considered here is the expected (mean) value of the time scale due to the $(1 / n)$ th highest wave crests, i.e.,

$$
E\left[T^{*}\left(w_{c}\right) \mid w_{\mathcal{c}}>w_{c 1 / n}\right]=n \int_{w_{c 1 / n}}^{\infty} T^{*}\left(w_{c}\right) p\left(w_{c}\right) d w_{\mathcal{c}}
$$

where $T^{*}\left(w_{c}\right)$ is the dimensionless time scale, and $p\left(w_{c}\right)=d P\left(w_{c}\right) / d w_{c}$ is the probability density function (pdf) of $w_{c}$. As in Myrhaug et al. [1], the present method is based on assuming that: (1) the free surface elevation is a stationary narrow-band process with zero expectation; (2) the time scale formula for regular waves provided in the previous section 
(Equations (3)-(5)) is valid for random waves as well. These assumptions are basically the same as those used by the authors in previous studies on pipeline scour due to random waves and partly justified by comparison with data (Myrhaug and Ong [8]).

In a narrow-band sea state $T_{w}=T_{p}$, where $T_{p}=2 \pi / \omega_{p}=2 \pi A_{r m s} / U_{r m s}$ using Equation (19). Taking $U=U_{m}, A=A_{m}$ and substituting this in Equations (3)-(8), and using from Equation (19) that $A_{m} / A_{r m s}=U_{m} / U_{r m s}$, Equation (3) can be re-arranged to obtain the time scale for individual narrow-band nonlinear irregular waves as (using that $\hat{U}_{m}=\mathrm{w}_{\mathrm{c}}$ by deleting terms of $\mathrm{O}\left(k_{p} a_{r m s}\right)$ as well as utilizing that $\left.\theta=\theta_{r m s} w_{c}{ }^{(2-d)}\right)$

$$
T^{*}\left(w_{c}\right)=\theta_{r m s}^{-5 / 3} F\left[U_{c w}\left(w_{c}\right)\right] w_{c}^{-5(2-d) / 3}
$$

where

$$
\begin{aligned}
U_{c w}\left(w_{c}\right) & =\frac{U_{c}}{U_{r m s}} /\left(w_{c}+\frac{U_{c}}{U_{r m s}}\right) \\
\theta_{r m s} & =\frac{\frac{1}{2} c\left(\frac{A_{r m s}}{z_{0}}\right)^{-d} U_{r m s}^{2}}{g(\gamma-1) d_{50}}
\end{aligned}
$$

Thus, the mean of the time scale due to the $(1 / n)$ th highest wave crests is obtained by substituting Equations (21)-(23) in Equation (20). Using the results in Appendix A gives

$$
w_{c 1 / n}=\sqrt{8} \alpha(\ln n)^{1 / \beta}
$$

where $\alpha$ and $\beta$ are the Weibull parameters given in Equations (A4) and (A5), respectively.

Concerning the Shields parameter, it is not obvious which value is the most relevant to use corresponding to live-bed scour. However, as in Ong et al. [15] and Myrhaug et al. [1], the corresponding statistical values of the time scale of scour and the Shields parameter are used (see Equation (45) in Ong et al. [15]).

$$
E\left[\theta_{c} \mid w_{c}>w_{c 1 / n}\right]=n(\sqrt{8} \alpha)^{2-d} \Gamma\left(1+\frac{2-d}{\beta}, \ln n\right)
$$

Here, $\theta_{c}=\theta_{m} / \theta_{r m s}$ is the normalized maximum Shields parameter under the wave crest for individual nonlinear random waves, $\theta_{m}$ is defined in Equation (6), where $\tau_{w}$ is replaced with $\tau_{m}$, i.e., the maximum bed shear stress beneath the wave crest for single nonlinear irregular waves, $\theta_{r m s}$ is given in Equation $(28)$, and $\Gamma(\bullet, \bullet)$ is the incomplete gamma function. For linear waves $\alpha=1 / \sqrt{8}, \beta=2$.

\section{Results and Discussion}

\subsection{Parameter Study}

Myrhaug et al. [1] provided results for 2D and 3D nonlinear irregular waves alone. Thus, the present results extend those given in the latter work by combining waves and current. In this case, $\theta_{r m s}$ and $U_{c w r m s}=U_{c} /\left(U_{c}+U_{r m s}\right)$ (Sumer and Fredsøe [3]) depend on the wave steepness $S_{1}$ (Equation (A2)) and the Ursell number $U_{R}$ (Equation (A3)) via the Weibull parameters $\alpha$ and $\beta$ (Equations (A4) and (A5), respectively). This is obvious by re-arranging Equations (A4), (A5) and (23) and $U_{c w r m s}$ to, respectively,

$$
\begin{gathered}
S_{1}=\frac{\sqrt{2}}{\pi} k_{p} a_{r m s} \tanh k_{p} h \\
U_{R}=\frac{2 \sqrt{2} k_{p} a_{r m s}}{\left(k_{p} h\right)^{3}} \\
\theta_{r m s}=\frac{\frac{1}{2} c\left(\frac{A_{r m s}}{z_{0}}\right)^{-d} U_{r m s}^{2}}{g(\gamma-1) d_{50}} ; U_{r m s}=\omega_{p} A_{r m s}, A_{r m s}=\frac{a_{r m s}}{\sinh k_{p} h}
\end{gathered}
$$




$$
U_{c w r m s}=\frac{U_{c}}{U_{c}+\frac{\omega_{p} a_{r m s}}{\sinh k_{p} h}}
$$

The parameter study is valid for $H_{s}=3 \mathrm{~m}, T_{p}=7.9 \mathrm{~s}, d_{50}=1 \mathrm{~mm}, \gamma=2.65$ (as for quartz sand). Thus, the results presented in Figure 1 for $E\left[T^{*}\right]$ versus $U_{c w r m s}$ are obtained by combining Equations (26)-(29) to cover the range of $U_{c w r m s}$ up to $0.5, S_{1}<0.15, U_{R}$ $<1$ (see Appendix A), and ensuring live-bed conditions for $\theta_{r m s}>0.05$. The results are exemplified taking $n=10$, although the most appropriate statistical value of the time scale corresponding to the equilibrium scour depth is not conclusive; it is judged by the designer depending on the problem considered.

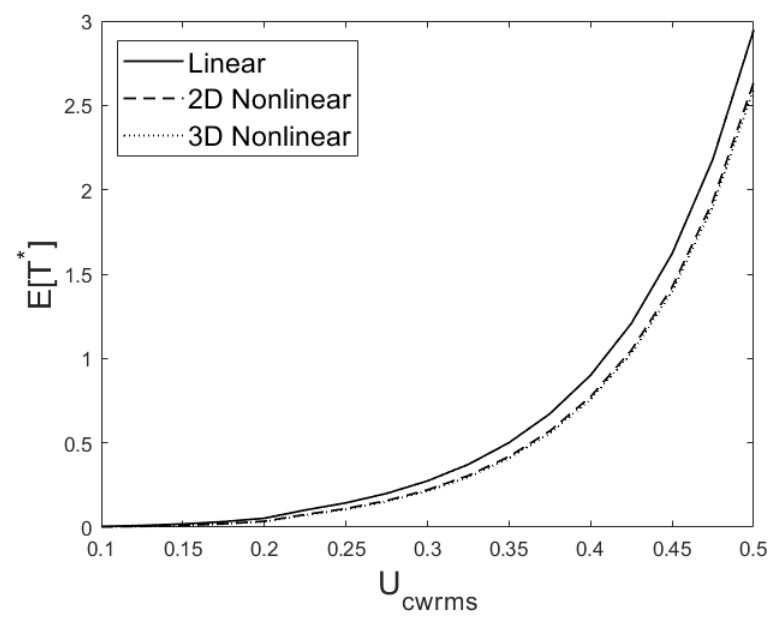

Figure 1. Expected value of nondimensional time scale for scour below pipelines for linear, 2D and $3 \mathrm{D}$ nonlinear random waves plus current versus $U_{\text {cwrms }}$.

From Figure 1, it appears for random waves and current that the effect of the current is to increase the time scale, i.e., the scour develops slower when a current is added for a given wave condition. This is an inherent feature of the Larsen et al. [4] model (which the present method is based on) and is expected on physical grounds (see their paper for more details). Moreover, the time scale is smaller for 2D and 3D nonlinear waves than for linear waves; the time scale for 3D waves is slightly smaller than for $2 \mathrm{D}$ waves. The lower time scale for 2D nonlinear waves than for linear waves is caused by the higher wave crests for nonlinear waves, i.e., the scour develops faster for nonlinear waves than for linear waves. The smaller time scale for 3D waves than for $2 \mathrm{D}$ waves is due to the higher wave crests for 3D waves than for 2D waves, which is caused by the smaller wave set-down effects for short-crested than for long-crested waves as described in the last paragraph of Appendix A. Thus, the scour develops faster for 3D waves than for 2D waves.

The results can alternatively be examined by comparing the nonlinear results with the corresponding linear results for $2 \mathrm{D}$ and $3 \mathrm{D}$ waves. The nonlinear-to-linear ratios of the mean time scale is denoted as $R 1$. Figure 2 shows $R 1$ versus $U_{\text {cwrms }}$ for $2 \mathrm{D}$ and $3 \mathrm{D}$ waves. It appears that $R 1$ increases as $U_{c w r m s}$ increases, i.e., the difference between the time scales for nonlinear and linear waves decreases as the current increases; the time scale for 3D waves is slightly smaller than for $2 \mathrm{D}$ waves and the difference decreases as $U_{\text {cwrms }}$ increases. The ratios increase from about 0.4 to about 0.9 as $U_{\text {cwrms }}$ increases from 0.1 to 0.5 . 


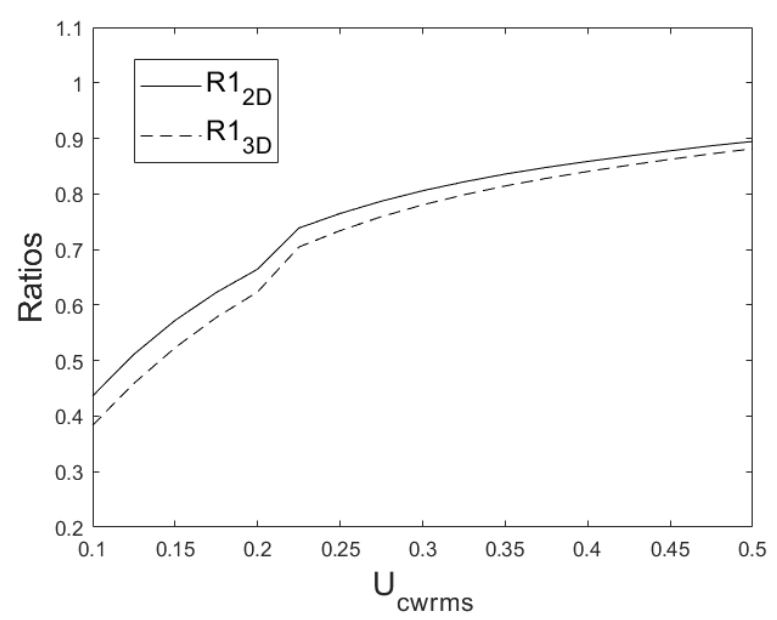

Figure 2. Nonlinear to linear ratio for $2 \mathrm{D}, \mathrm{R} 1_{2 \mathrm{D}}$, waves and $3 \mathrm{D}, \mathrm{R} 1_{3 \mathrm{D}}$, waves versus $U_{c w r m s}$.

Another interesting feature is to compare the $3 \mathrm{D}$ and $2 \mathrm{D}$ results. The ratio between the mean time scales for 3D and 2D nonlinear waves is denoted as R2. Figure 3 depicts $R 2$ versus $U_{c w r m s}$, showing that $R 2$ increases as $U_{c w r m s}$ increases; from about 0.88 to about 0.98 as $U_{c w r m s}$ increases from 0.1 to 0.5 . This reflects that the effect of increasing the current is to reduce the difference in time scales between 3D and 2D nonlinear waves as demonstrated in Figure 2.

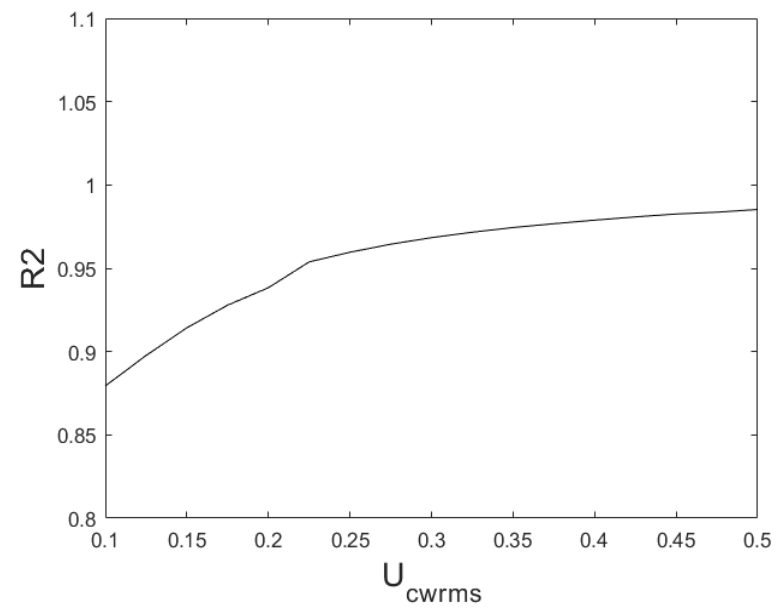

Figure 3. Three-dimensional nonlinear to two-dimensional nonlinear ratio, R2, versus $U_{c w r m s}$.

\subsection{Example Calculation}

This example is provided to demonstrate the application of the method. The following flow conditions are considered:

1. Significant wave height, $H_{s}=3 \mathrm{~m}$

2. Spectral peak period, $T_{p}=7.9 \mathrm{~s}$, corresponding to $\omega_{p}=0.795 \mathrm{rad} / \mathrm{s}$

3. Water depth, $h=10 \mathrm{~m}$

4. Current speed, $U_{c}=0.2 \mathrm{~m} / \mathrm{s}$.

Median grain size diameter (coarse sand according to Soulsby [11]),

$\mathrm{d}_{50}=1 \mathrm{~mm}$,

$\gamma=2.65$ (as for quartz sand),

Pipeline diameter, $D=1 \mathrm{~m}$.

Table 1 provides the calculated quantities, where $S_{1}$ and $U_{R}$ are given by replacing $T_{1}$ and $k_{1}$ with $T_{p}$ and $k_{p}$, respectively, due to the narrow-banded wave process. The results are for $n=10$, although the statistical value of the time scale corresponding to the equilibrium 
scour depth is not conclusive; it is judged by the designer depending on the problem considered.

Table 1. Example calculation with $h=10 \mathrm{~m}, d_{50}=1 \mathrm{~mm}, D=1 \mathrm{~m}, n=10$.

\begin{tabular}{lr}
\hline$a_{r m s}(m)$ & 1.06 \\
$k_{p}(\mathrm{rad} / \mathrm{m})$ & 0.09 \\
$S_{1}$ & 0.031 \\
$U_{R}$ & 0.370 \\
$\alpha_{2 D}, \beta_{2 D}$ & $0.4018,1.9468$ \\
$\alpha_{3 D}, \beta_{3 D}$ & $0.3911,1.7876$ \\
$A_{\text {rms }}(m)$ & 1.03 \\
$U_{\text {rms }}(\mathrm{m} / \mathrm{s})$ & 0.821 \\
$U_{\text {cwrms }}=U_{c} /\left(U_{c}+U_{r m s}\right)$ & 0.196 \\
$A_{\text {rms }} / z_{0}$ & 12360 \\
$c, d$ & $0.112,0.25$ \\
$\theta_{\text {rms }}$ & 0.22 \\
Time scale (waves alone) & \\
$T_{\text {lin }}(\mathrm{s})$ & 382 \\
$T_{2 D}(\mathrm{~s})$ & 252 \\
$T_{3 D}(\mathrm{~s})$ & 237 \\
Time scale (waves plus current) & \\
$T_{\text {lin }}(\mathrm{s})$ & 387 \\
$T_{2 D}(\mathrm{~s})$ & 255 \\
$T_{3 D}(\mathrm{~s})$ & 238 \\
Shields parameter, $\theta_{m}=\theta_{c} \theta_{r m s}$ & \\
$\theta_{\text {clin }}$ & 2.83 \\
$\theta_{\text {mlin }}$ & 0.627 \\
$\theta_{\text {cnonlin, } 2 D}$ & 3.65 \\
$\theta_{\text {cnonlin, }, 3 D}$ & 3.84 \\
$\theta_{\text {mnonlin, } 2 D}$ & 0.807 \\
$\theta_{\text {mnonlin, } 3 D}$ & 0.850 \\
\hline
\end{tabular}

The rms value of the wave amplitude corresponds to that for a Rayleigh distribution, i.e., $a_{r m s}=H_{s} /(2 \sqrt{2})$. Moreover, $A_{r m s} / \mathrm{z}_{0}$ (with $\mathrm{z}_{0}=d_{50} / 12$ ) exceeds 11,000 , and accordingly $(\mathrm{c}, \mathrm{d})=(0.112,0.25)$. Further, $\theta_{r m s}$ exceeds the threshold Shields parameter $\theta_{c r} \approx 0.05$ corresponding to live-bed conditions.

The expected value of the time scale due to the $(1 / 10)$ th highest wave crests is considered. For linear waves and current as well as nonlinear waves and current, it is demonstrated that by adding the current, the time scale increases as discussed in Section 4.1. For waves alone the nonlinear to linear ratios for 2D and 3D waves are 0.660 and 0.620 , respectively. For waves and current, the nonlinear to linear ratios for $2 \mathrm{D}$ and $3 \mathrm{D}$ waves are 0.659 and 0.615 , respectively. Thus, $3 \mathrm{D}$ waves give slightly smaller values than $2 \mathrm{D}$ waves, i.e., as a result of the higher wave crests for $3 \mathrm{D}$ waves than for $2 \mathrm{D}$ waves as referred to in Section 4.1.

One should note that, for both linear and nonlinear waves, the Shields parameter $\theta_{m}$ exceeds the $\theta_{c r}$ corresponding to live-bed conditions; 3D waves give a slightly larger value than $2 \mathrm{D}$ waves.

\section{Summary and Conclusions}

A practical stochastic method is derived for the time scale of equilibrium pipeline scour due to 2D (long-crested) and 3D (short-crested) nonlinear irregular waves and current for wave-dominant flow valid for $U_{c w r m s}=U_{c} /\left(U_{c}+U_{r m s}\right)$ in the range 0 to 0.5 , wave steepness $S_{1}$ in the range 0 to 0.15 , the Ursell number $U_{R}$ in the range 0 to 1 , and live-bed conditions, i.e., $\theta_{r m s}>0.05$.

The main conclusions are:

1. For both $2 \mathrm{D}$ and $3 \mathrm{D}$ nonlinear waves, the time scale of equilibrium scour is smaller than for linear waves for a given wave and current condition. This is caused by the 
higher wave crests for nonlinear waves than for linear waves, i.e., the scour develops faster for nonlinear than for linear waves.

2. The time scale for 3D nonlinear waves is smaller than that for $2 \mathrm{D}$ nonlinear waves. This is due to the higher wave crests for 3D waves than for 2D waves, which is caused by the smaller wave set-down effects for 3D than for 2D waves.

3. The effect of the current is to increase the time scale. The present parameter study for $H_{s}=3 \mathrm{~m}, T_{p}=7.9 \mathrm{~s}, d_{50}=1 \mathrm{~mm}$ shows that: (i) for $2 \mathrm{D}$ and $3 \mathrm{D}$ waves, the nonlinearto-linear ratios of the mean time scale increase from about 0.4 to about 0.9 as $U_{c w r m s}$ increases from 0.1 to 0.5 ; (ii) the $3 \mathrm{D}$ nonlinear to $2 \mathrm{D}$ nonlinear ratio of the mean time scale increases from about 0.88 to about 0.98 as $U_{\text {cwrms }}$ increases from 0.1 to 0.5 .

Although the method is simple, it should be useful as a first-order approximation representing the stochastic features of the time scale for pipeline scour beneath $2 \mathrm{D}$ and $3 \mathrm{D}$ nonlinear irregular waves and current for wave-dominant flow. However, comparison with data is needed before conclusions regarding its validity can be made, but in the meantime the method should be suitable to use for the practical engineering assessment of pipeline scour for the given flow conditions.

Author Contributions: Conceptualization, D.M. and M.C.O.; methodology, D.M. and M.C.O.; software, M.C.O.; validation, D.M. and M.C.O.; formal analysis, D.M. and M.C.O.; investigation, D.M. and M.C.O.; data curation, M.C.O; writing-original draft preparation, D.M.; writing-review and editing, D.M. and M.C.O.; visualization, M.C.O. All authors have read and agreed to the published version of the manuscript.

Funding: This research received no external funding.

Institutional Review Board Statement: Not applicable.

Informed Consent Statement: Not applicable.

Data Availability Statement: Data sharing not applicable.

Acknowledgments: There is no acknowledgment.

Conflicts of Interest: The authors declare no conflict of interest.

\section{Appendix A Crest Height Distribution}

The Forristall [10] parametric crest height distribution is based on simulations using second-order theory. The simulations were based on the Sharma and Dean [16] theory including both sum-frequency and difference-frequency effects performed both for longcrested (2D) and short-crested (3D) random waves. The results were represented by a two-parameter Weibull distribution with the cdf

$$
P\left(w_{c}\right)=1-\exp \left[-\left(\frac{w_{c}}{\sqrt{8} \alpha}\right)^{\beta}\right] ; w_{c} \geq 0
$$

that was fitted to the simulated wave data. The Weibull parameters $\alpha$ and $\beta$ were estimated from the fit to the simulated wave data based on the wave steepness $S_{1}$ and the Ursell number $U_{R}$ defined by, respectively,

$$
\begin{gathered}
S_{1}=\frac{2 \pi}{g} \frac{H_{s}}{T_{1}^{2}} \\
U_{R}=\frac{H_{s}}{k_{1}^{2} h^{3}}
\end{gathered}
$$

One should notice that Forristall provided results for $S_{1}$ in the range 0 to 0.15 and $U_{R}$ in the range 0 to 1 . Here, $H_{s}$ is the significant wave height, $T_{1}$ is the spectral mean period, and $k_{1}$ is the wave number corresponding to $T_{1}$. One should note that $H_{s}=2 \sqrt{2} a_{r m s}$ when the wave amplitude $a$ is Rayleigh distributed. The wave steepness and the Ursell number 
represent the nonlinearity of irregular waves in finite water depth. For zero steepness and zero Ursell number, the fits match the Rayleigh distribution, i.e., $\alpha=1 / \sqrt{8}=0.3536$ and $\beta=2$, for both $2 \mathrm{D}$ and $3 \mathrm{D}$ linear waves. For $2 \mathrm{D}$ waves

$$
\begin{aligned}
& \alpha_{2 D}=0.3536+0.2892 S_{1}+0.1060 U_{R} \\
& \beta_{2 D}=2-2.1597 S_{1}+0.0968 U_{R}^{2}
\end{aligned}
$$

and for 3D waves

$$
\begin{aligned}
& \alpha_{3 D}=0.3536+0.2568 S_{1}+0.0800 U_{R} \\
& \beta_{3 D}=2-1.7912 S_{1}-0.5302 U_{R}+0.284 U_{R}^{2}
\end{aligned}
$$

The wave set-down effects are smaller for $3 \mathrm{D}$ waves than for $2 \mathrm{D}$ waves in finite water depth due to the fact that the second-order negative difference-frequency terms are smaller for short-crested than for long-crested waves (Forristall [10]). Thus, the wave crest heights are higher for 3D waves than for $2 \mathrm{D}$ waves.

\section{References}

1. Myrhaug, D.; Ong, M.C.; Dyrseth, S. Time scales for scour below pipelines and around vertical piles due to nonlinear random waves. In Scour and Erosion Proceedings of the 8th International Conference on Scour and Erosion, Oxford, UK, 12-15 September 2016; CRC Press: Boca Raton, FL, USA, 2016; pp. 247-254.

2. Whitehouse, R.J.S. Scour at Marine Structures. A Manual for Practical Applications; Thomas Telford: London, UK, 1998.

3. Sumer, B.M.; Fredsøe, J. The Mechanics of Scour in the Marine Environment; World Scientific: Singapore, 2002.

4. Larsen, B.E.; Fuhrman, D.R.; Sumer, B.M. Simulation of wave-plus-current scour beneath submarine pipelines. J. Waterw. Port Coast. Ocean Eng. 2016, 142, 04016003. [CrossRef]

5. Zhang, Q.; Draper, S.; Cheng, L.; An, H. Time scale of local scour around pipelines in current, waves, and combined waves and current. J. Hydraul. Eng. 2017, 143, 04016093. [CrossRef]

6. Zang, Z.; Tang, G.; Cheng, L. Time scale of scour below submarine pipeline under combined waves and currents with oblique incident angle. In Proceedings of the ASME 36th International Conference on Ocean, Offshore and Arctic Engineering, Trondheim, Norway, 25-30 June 2017. Paper No. OMAE2017-62365.

7. Sumer, B.M.; Fredsøe, J. Scour around pipelines in combined waves and current. In Proceedings of the ASME 15th International Conference on Ocean, Offshore and Arctic Engineering, Florence, Italy, 15 June 1996; Volume 5, pp. 595-602.

8. Myrhaug, D.; Ong, M.C. Random wave-induced scour around marine structures using a stochastic method. Mar. Technol. Eng. 2011, 1, 537-562.

9. Myrhaug, D.; Ong, M.C. Long- and short-crested random wave-induced scour below pipelines. Proc. Inst. Civ. Eng. Marit. Eng. 2011, 164, 173-184. [CrossRef]

10. Forristall, G.Z. Wave crest distributions: Observations and second-order theory. J. Phys. Oceanogr. 2000, 30, 1931-1943. [CrossRef]

11. Soulsby, R.L. Dynamics of Marine Sands. A Manual for Practical Applications; Thomas Telford: London, UK, 1997.

12. Myrhaug, D.; Holmedal, L.E.; Simons, R.R.; MacIver, R.D. Bottom friction in random waves plus current flow. Coast. Eng. 2001, 43, 75-92. [CrossRef]

13. Catano-Lopera, Y.A.; Garcia, M.H. Geometry of scour hole, and the influence of the angle of attack on the burial of final length cylinders under combined flows. Ocean Eng. 2007, 34, 856-869. [CrossRef]

14. Dean, R.G.; Dalrymple, R.A. Water Wave Mechanics for Engineers and Scientists; Prentice-Hall, Inc.: Upper Saddle River, NJ, USA, 1984

15. Ong, M.C.; Myrhaug, D.; Hesten, P. Scour around vertical piles due to long-crested and short-crested nonlinear random waves plus a current. Coast. Eng. 2013, 73, 106-114. [CrossRef]

16. Sharma, J.N.; Dean, R.G. Second-order directional seas and associated wave forces. Soc. Pet. Eng. J. 1981, 21, 129-140. [CrossRef] 